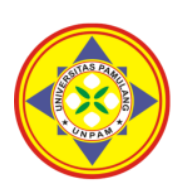

\title{
PENGARUH DISIPLIN DAN MOTIVASI KERJA TERHADAP KINERJA KARYAWAN PT. ARYA LINGGA MANIK
}

\author{
${ }^{1 *}$ Arief Budi Santoso, ${ }^{2}$ Muldani \\ Universitas Pamulang, Tangerang Selatan, Banten, Indonesia \\ *dosen01152@unpam.ac.id
}

\begin{abstract}
Abstrak
Penelitian ini bertujuan untuk mengetahui apakah terdapat pengaruh Disiplin dan Motivais Kerja terhadap Kinerja Karyawan PT. Arya Lingga Manik. Metode Penelitian ini dilakukan dengan metode kuantitatif pendekatan asosiatif. Teknik sampling yang dipakai adalah sampel jenuh dengan jumlah sampel sebanyak 61 responden. Pengumpulan data yang dilakukan dengan mengamati langsung objek penelitian, memberikan kuisioner atau angket kepada pihak-pihak yang berwenang dengan mengajukan daftar yang disusun secara sistematis dan logis. Teknik analisis data yang digunakan adalah uji validitas, uji reliabilitas, uji regresi linier sederhana, uji regresi berganda, uji normalitas, uji durbin-watson, uji koefisisen determinasi, uji heteroskesdastisitas, uji t hipotesis dan uji $\mathrm{f}$ hipotesis. Berdasarkan hasil penelitian yang penulis tulis, dapat disimpulkan bahwa Disiplin dan Motivasi Kerja berpengaruh signifikan terhadap Kinerja Karyawan dengan persamaan regresi $Y=3,006$ $+0,354$ X1 + 0.528 X2 Nilai koefisien determinasi diperoleh sebesar 53,2\% artinya variabel bebas memiliki tingkat pengaruh yang cukup kuat terhadap variabel terikat sedangkan sisanya sebesar 46,80 $\%$ dipengaruhi faktor lain.
\end{abstract}

Kata Kunci: Disiplin, Motivasi Kerja dan Kinerja Karyawan

Abstract

This study aims to see whether there is an effect of Work Discipline and Motivation on Employee Performance at PT. Arya Lingga Manik. Methods This research was conducted with a quantitative method of associative approach. The sampling technique used was saturated sample with a total sample size of 61 respondents. Data collection is carried out by storing directly from the object of research, giving a questionnaire or questionnaire to the parties who come by submitting a list that is arranged systematically and logically. The data analysis technique used is validity test, reliability test, simple linear regression test, multiple regression test, normality test, Durbin-Watson test, determination coefficient test, heteroskesdasticity test, hypothesis $t$ test and hypothesis $f$ test. Based on the results of the research that the author wrote, it can be denied that work discipline and motivation have a significant effect on employee performance with the regression equation $Y=3.006+0.354$ $\mathrm{X} 1+0.528 \mathrm{X} 2$ The value of the coefficient of determination is $53.2 \%$, meaning that the independent variable has a strong enough level of influence on the variable. while the rest amounted to $46.80 \%$ other factors.

Keywords: Discipline, Work Motivation and Employee Performance

\section{PENDAHULUAN}

Setiap organisasi baik negeri maupun swasta berusaha untuk mencari keunggulan kompetitif, sementara pesaing juga melakukan hal yang serupa. Kondisi tersebut merupakan konsekuensi dari globalisasi yang berkembang dalam dunia bisnis yang membuat persaingan menjadi sangat ketat, tidak terprediksi dan tidak pasti. Perubahan yang terjadi setiap saat dan semakin cepat ini menuntut organisasi untuk mampu beradaptasi dengan cepat dan tangkas, untuk memperoleh keunggulan kompetitif. Organisasi membutuhkan strategi baru yang lebih sesuai dengan kondisi internal dan eksternal organisasi saat ini.

Kinerja sebagai kemajuan dan tingkat penyelesaian suatu pekerjaan baik kualitas ataupun kuantitasnya yang harus meningkat dari waktu ke waktu. Dengan kata lain kinerja adalah hasil pelaksanaan suatu pekerjaan, baik bersifat fisik/ 
material maupun non fisik/non material. Setiap pekerja dalam melaksanakan tugastugasnya sebagaimana terdapat didalam pekerjaan/ jabatan perlu dinilai hasil kerjanya.

Sejatinya kinerja yang baik dan optimal akan mewujudkan keberhasilan perusahaan dalam mencapai tujuan yang telah di tetapkan. Akan tetapi dalam hal ini, menurut analisa penulis berdasarkan data yang di dapat di awal penelitian mengenai kinerja karyawan PT. Arya Lingga Manik yaitu perusahaan yang bergerak dalam bidang produksi dan Penjualan Properti, dinilai belum optimal dan cenderung mengalami penurunan kinerja. Hal terlihat dari pencapaian hasil kinerja karyawan yang tidak mencapai target perusahaan.

Tabel 1. Data Realisasi Pembangunan Rumah di Proyek Perumahan Panorama Bali Residence Ciseeng - Bogor

\begin{tabular}{|c|c|c|c|}
\hline Tahun & $\begin{array}{c}\text { Target Pembangunan Rumah } \\
\text { (Unit/Tahun) }\end{array}$ & $\begin{array}{c}\text { Realisasi Pembangunan } \\
\text { Rumah (Unit/Tahun) }\end{array}$ & $\begin{array}{c}\text { Persentase } \\
\text { Pencapaian }\end{array}$ \\
\hline 2017 & 1.000 & 705 & $70.5 \%$ \\
\hline 2018 & 1.000 & 542 & $54.2 \%$ \\
\hline 2019 & 1.000 & 675 & $67.5 \%$ \\
\hline $\begin{array}{c}\text { Rata- } \\
\text { rata }\end{array}$ & 1.000 & 640 & $64 \%$ \\
\hline
\end{tabular}

Sumber: PT. Arya Lingga Manik (2020)

Kinerja merupakan hasil akhir dari setiap proses pekerjaan yang dilakukan oleh setiap karyawan, fungsi dari kinerja ini sebagai tolak ukur penilaian hasil yang sebelumnya sudah menjadi acuan untuk dijadikan sebagai tujuan utama, dari data diatas adanya naik dan turun dari pencapaian target yang telah ditentukan oleh perusahaan setiap tahunnya, hal ini berarti tingkat kinerja yang dilakukan oleh karyawan dirasa masih belum maksimal dalam menjalankan pekerjaannya, maka dari itu perlu diminimalisir sebaik mungkin hal - hal yang mempengaruhi dari kinerja karyawan itu sendiri.

Tujuan dan kemampuan mempengaruhi tingkat kedisiplinan karyawan. Tujuan yang akan dicapai harus jelas dan ditetapkan secara ideal serta cukup menantang bagi kemampuan karyawan. Teladan pimpinan sangat berperan dalam menentukan kedisiplinan Tabel 2. Rekapan Absensi Karyawan PT. Arya Lingga Manik Pada Proyek Perumahan Panorama Bali Residence Ciseeng-Bogor Periode Tahun 2017-2019

\begin{tabular}{|c|c|c|c|c|}
\hline \multirow{2}{*}{ Tahun } & \multirow{2}{*}{$\begin{array}{c}\text { Jumlah } \\
\text { Karyawan }\end{array}$} & \multirow{2}{*}{ Hari Kerja } & Absensi & $\begin{array}{c}\text { Persentase } \\
\text { Absensi(Alpha) }\end{array}$ \\
\cline { 4 - 5 } & & & Alpha & \\
\hline 2017 & 61 & 289 & 19 & $7 \%$ \\
\hline 2018 & 61 & 289 & 17 & $6 \%$ \\
\hline 2019 & 61 & 294 & 27 & $9 \%$ \\
\hline
\end{tabular}

Sumber: PT. Arya Lingga Manik (2020)

Dalam pada tabel di atas berupa data absensi karyawan PT. Arya Lingga Manik karyawan karena pimpinan dijadikan teladan dan panutan oleh para bawahannya pimpinan harus memberi contoh yang baik, berdisiplin baik, jujur, adil, serta sesuai kata dengan perbuatan. Dengan teladan pimpinan yang baik kedisiplinan bawahan pun akan ikut baik, jika teladan pimpinan kurang baik para bawahan pun akan kurang disiplin.

Pada akhirnya karyawan yang mempunyai disiplin yang tinggi akan menghasilkan kinerja yang baik karena waktu bekerja dimanfaatkan sebaik mungkin untuk melaksanakan pekerjaannya sesuai yang telah ditetapkan masing-masing perusahaan, tetapi hal tersebut tidak kelihatan di PT. Arya Lingga Manik yang dilakukan sebagian karyawan, ada beberapa yang tidak disiplin mengenai absensi, sehingga diperkirakan mempengaruhi terhadap pencapaian target

yang telah di tetapkan perusahaan.
Manik Pada Proyek Perumahan Panorama Bal

Pada Proyek Perumahan Panorama Bali Residence Ciseeng Bogor, menunjukan 
karyawan yang tidak hadir tanpa keterangan yang jelas (Alpha) cukup banyak dalam kurun waktu 3 tahun terakhir dan dirasa masih perlu diperbaiki mengenai absensi agar terciptanya kedisiplinan.

Tingginya persentasi ketidakhadiran dan keterlambatan pegawai PT. Arya Lingga Manik juga mencerminkan rendahanya motivasi pegawai. Pegawai yang memiliki motivasi tinggi tentu akan berusaha seoptimal mungkin untuk mencapai tujuan organisasi. Sementara pegawai dengan motivasi rendah

Tabel 3. Rekap Pemberian Reward Tahunan Perumahan Panorama Bali Residence Ciseeng-Bogor Periode Tahun 2017-2019

\begin{tabular}{|c|c|c|c|}
\hline Tahun & $\begin{array}{c}\text { Jumlah } \\
\text { Karyawan }\end{array}$ & $\begin{array}{c}\text { Jumlah Penerima } \\
\text { Reward (orang) }\end{array}$ & $\begin{array}{c}\text { Persentase penerima } \\
\text { Reward }\end{array}$ \\
\hline 2017 & 61 & 5 & $9 \%$ \\
\hline 2018 & 61 & 8 & $14 \%$ \\
\hline 2019 & 61 & 7 & $12 \%$ \\
\hline
\end{tabular}

Sumber: PT. Arya Lingga Manik (2020)

Dari data di atas terlihat hanya sedikit karyawan yang menerima reward tahunan dari perusahaan, bahkan penerima reward tahunan tidak mampu mencapai 50\% dari jumlah karyawan sesuai dengan apa yang di harapkan perusahaan. Hal ini menunjukan rendahnya motivasi kerja karyawan PT. Arya Lingga Manik dalam mencapai target kerja yang di harapkan perusahaan.

\section{TINJAUAN PUSTAKA}

1. Disiplin

Menurut Hasibuan (2020:193) mengatakan bahwa "Disiplin kesadaran dan kesediaan seseorang menaati semua peraturan perusahaan dan normanorma sosial yang berlaku".

Menurut Heidjrachman dan Husnan dalam Prihantoro (2015:15) mengungkapkan "Disiplin adalah setiap perseorangan dan juga kelompok yang menjamin adanya kepatuhan terhadap perintah dan berinisiatif untuk melakukan suatu tindakan yang di perlukan seandainya tidak ada perintah".

Secara umum disiplin (Discipline) adalah peraturan yang harus dipatuhi cenderung malas untuk bekerja optimal. Motivasi merupakan faktor yang menimbulkan semangat atau dorongan kerja dalam diri pegawai dan untuk mencapai tujuan organisasi.

Indikator lain yang menunjukan rendahnya motivasi kerja karyawan PT. Arya Lingga Manik dapat di lihat dari tabel pemberian Reward tahunan yaitu berupa hadiah berupa barang-barang elektronik yang di berikan oleh perusahaan khusus kepada karyawan yang di nilai berprestasi yang telah sesuai dengan penilaian KPI (Key Performance Indikator) perusahaan. aryawan PT. Arya Lingga Manik Pada Proyek

atau diikuti sesuai dengan ketetapan yang berlaku pada suatu organisasi, kedisiplinan merupakan fungsi operatif dari manajemen sumber daya manusia yang terpenting karena semakin baik disiplin karyawan, semakin tinggi prestasi kerja yang dapat dicapainya tanpa disiplin karyawan yang baik, sulit bagi organisasi perusahaan mencapai hasil yang optimal.

2. Motivasi Kerja

Menurut Teori kebutuhan motivasi Maslow dalam Syaifuddin (2018:50) "motivasi adalah dorongan untuk memenuhi kebutuhan yang bertingkattingkat dari yang paling sederhana hingga yang paling tinggi berdasarkan kepetingannya".

Menurut Mangkunegara (2017:61) "Motivasi adalah merupakan kondisi atau energi yang menggerakan diri karyawan yang terarah atau tertuju untuk mencapai tujuan organisasi perusahaan". definisi menurut para ahli di atas mengenai motivasi dapat di simpulkan secara umum bahwa motivasi adalah dorongan yang bisa berasal dalam mau

Berikut adalah pengertian- Dari 
luar diri seorang individu untuk melakukan suatu kegiatan dalam mencapai tujuan maupun untuk memenuhi kebutuhanya.

3. Kinerja Karyawan

Menurut Mangkunegara (2017:9) kinerja berasal dari pengertian kata perfomance yaitu hasil kerja atau prestasi kerja. “Kinerja adalah hasil kerja secara kualitas dan kuantitas yang di capai oleh seseorang karyawan dalam melaksanakan tugasnya sesuai dengan tanggung jawab yang di berikan kepadanya".

Pengertian Kinerja secara umum Kinerja merupakan performance atau unjuk kerja, kinerja dapat pula diartikan sebagai prestasi kerja atau pelaksanaan kerja. Tingkat keberhasilan seseorang dalam menyelesaikan pekerjaannya disebut dengan istilah level of performance atau level kerja. Karyawan yang memiliki level kinerja yang tinggi merupakan karyawan yang produktivitas kerjanya tinggi, begitupun sebaliknya karyawan yang memiliki level kinerja tidak sesuai dengan standar yang ditetapkan maka karyawan tersebut merupakan karyawan yang tidak produktif.

\section{METODE}

Penelitian ini dilakukan di kantor PT. Arya Lingga Manik yang beralamat Jl. Pahlawan Seribu, Ruko CBD Bidex Blok F21 BSD City Tangerang Selatan dan juga di Kantor Proyek Perumahan Panorama Bali Residence yang beralamat Jl. Raya H.Usa Putat Nutug Ciseeng Bogor. Waktu Penelitian ini dilaksanakan selama 3 (Tiga) bulan yang dimulai dari bulan September November 2020.

Dalam penelitian populasinya adalah karyawan PT. Arya Lingga Manik Proyek Perumahan Panorama Bali Residence yang berjumlah 61 karyawan, dan tehnik pengambilan sampel menggunakan teknik sampling jenuh yaitu mengambil semua populasi menjadi sampel, Teknik pengumpulan data menggunakan uji instrumen data, uji prasyarat data dan uji statistik.

\section{HASIL DAN PEMBAHASAN}

1. Pembahasan Hasil Penelitian

Berdasarkan hasil penelitian yang telah diuraikan sebelumnya menunjukkan bahwa terdapat pengaruh positif dan signifikan baik secara parsial maupun simultan disiplin dan motivasi kerja terhadap kinerja karyawan. Berikut ini dipaparkan penjelasan atas jawaban dari hipotesis penelitian.

a. Pengaruh Disiplin (X1) Terhadap

Kinerja karyawan $(\mathrm{Y})$

Berdasarkan hasil penelitian ini didapatkan bahwa variabel Disiplin (X1) memiliki pengaruh terhadap Kinerja Karyawan (Y) Pada PT. Arya Lingga Manik. Pengaruh Disiplin terhadap Kinerja Karyawan dapat dijelaskan beberapa faktor.

Hasil penelitian ini, diperoleh nilai persamaan regresi $Y=10,013+0,588$ x1, Koefisien Determinasi sebesar 0,385 artinya variabel Disiplin (X1) mempunyai pengaruh yang cukup kuat sebesar 38,5\% terhadap variabel Kinerja Karyawan (Y), dan hasil uji hipotesis di peroleh nilai $\mathrm{t}$ hitung $>\mathrm{t}$ tabel $(6,071>2,001)$ dan nilai sig $(0,000$ $<0,05)$ dengan demikian H0 di tolak dan H1 di terima, maka dapat disimpulkan terdapat pengaruh yang positif dan signifikan antara Disiplin terhadap Kinerja Karyawan secara parsial (sendiri-sendiri) sehingga hipotesisnya diterima. Pemikiran di atas sejalan dengan penelitian terdahulu.

b. Pengaruh Motivasi kerja $\left(\mathrm{X}_{2}\right)$ Terhadap Kinerja karyawan $(Y)$

Berdasarkan hasil penelitian ini didapatkan bahwa variabel Motivasi Kerja (X2) memiliki pengaruh terhadap Kinerja Karyawan (Y) pada PT. Arya Lingga Manik. Pengaruh Motivasi Kerja terhadap Kinerja Karyawan dapat dijelaskan beberapa faktor. 
Hasil penelitian ini, diperoleh nilai persamaan regresi $\mathrm{Y}=5,838+$ $0,762 \times 2$, Koefisien Determinasi sebesar 0,433 artinya variabel Motivasi Kerja (X2) mempunyai pengaruh sebesar 43,3\% variabel Kinerja Karyawan (Y), dan hasil uji hipotesis di peroleh nilai $\mathrm{t}$ hitung $>\mathrm{t}$ tabel $(6,718>2,001)$ dan nilai sig $(0,000<0,05)$ dengan demikian dengan demikian $\mathrm{H}_{0}$ di tolak dan $\mathrm{H}_{2}$ di terima, maka dapat disimpulkan terdapat pengaruh yang positif dan signifikan antara Motivasi Kerja terhadap Kinerja Karyawan secara parsial (sendiri-sendiri) sehingga hipotesisnya diterima. Pemikiran di atas sejalan dengan penelitian terdahulu.

c. Pengaruh Disiplin $\left(X_{1}\right)$ dan Motivasi Kerja (X2) Secara Simultan Terhadap Kinerja karyawan $(\mathrm{Y})$

Berdasarkan hasil penelitian ini didapatkan bahwa variabel Disiplin (X1) dan Motivasi Kerja (X2) memiliki pengaruh positif terhadap Kinerja Karyawan (Y) pada PT. Arya Lingga Manik.

Hasil penelitian ini, diperoleh nilai persamaan regresi $Y=3,006+0,354 \times 1$ $+0.528 \times 2$ Nilai koefisien determinasi atau kontribusi pengaruh secara simultan sebesar $53,2 \%$ artinya variabel Disiplin (X1) dan variabel Motivasi Kerja (X2) mempunyai pengaruh yang cukup kuat terhadap variabel Kinerja Karyawan (Y), dan hasil uji hipotesis di peroleh nilai $t$ hitung $>\mathrm{t}$ tabel $(32,981>3,15)$ dan nilai sig $(0,000<0,05)$ maka Dengan demikian $\mathrm{H}_{0}$ ditolak dan $\mathrm{H}_{3}$ diterima. Artinya terdapat pengaruh yang signifikan secara simultan antara Disiplin dan Motivasi Kerja terhadap Kinerja Karyawan PT. Arya Lingga Manik . Pemikiran di atas sejalan dengan penelitian terdahulu.

\section{PENUTUP}

\section{Kesimpulan}

Berdasarkan uraian pada bab-bab sebelumnya, dan dari hasil analisis serta pembahasan mengenai Disiplin dan Motivasi Kerja terhadap Kinerja Karyawan, sebagai berikut :

1. Disiplin pada PT. Arya Lingga Manik pada proyek Panorama Bali Residence masuk ke dalam kategori baik. Hal ini dapat dibuktikan dari akumulasi ratarata skor sebesar 3,94 nilai ini bila mengacu pada skala interval masuk pada interval 3,40 - 4,20 yang memiliki interpretasi baik.

2. Motivasi Kerja pada PT. Arya Lingga Manik pada proyek Panorama Bali Residence masuk masuk ke dalam kategori baik. Hal ini dapat dibuktikan dari akumulasi rata-rata skor sebesar 3,95 nilai ini bila mengacu pada skala interval masuk pada interval 3,40 - 4,20 yang memiliki interpretasi baik.

3. Kinerja Karyawan pada PT. Arya Lingga Manik pada proyek Panorama Bali Residence masuk ke dalam kategori baik. Hal ini dapat dibuktikan dari akumulasi rata-rata skor sebesar 3,98 nilai ini bila mengacu pada skala interval masuk pada interval 3,40 - 4,20 yang memiliki interpretasi baik

4. Disiplin dan Motivasi Kerja berpengaruh signifikan terhadap Kinerja Karyawan dengan persamaan regresi $\mathrm{Y}=3,006+$ 0,354 X1 +0.528 X2. Nilai koefisien determinasi diperoleh sebesar 53,2\% artinya variabel bebas memiliki tingkat pengaruh yang cukup kuat terhadap variabel terikat sedangkan sisanya sebesar 46,80 \% dipengaruhi faktor lain. Uji hipotesis diperoleh nilai $\mathrm{F}$ hitung $>\mathrm{F}$ tabel atau $(32,981>3,15)$, hal tersebut juga diperkuat dengan probability signifikansi $0,000<0,05$. Dengan demikian $\mathrm{H} 0$ ditolak dan $\mathrm{H} 3$ diterima. Artinya terdapat pengaruh signifikan secara simultan antara Disiplin dan Motivasi Kerja Terhadap Kinerja Karyawan di PT. Arya Lingga Manik.

\section{Saran}

Berbagai kegiatan yang dilakukan baik dari menganalisa sampai dengan menguraikan kesimpulan maka penulis mencoba memberikan saran. Dimana saran 
ini akan menjadi tambahan bahan evaluasi untuk perusahaan sendiri. Sebagai berikut :

1. Pada hasi analisisa kuesioner mengenai Disiplin pernyataan yang paling lemah adalah pada indikator kehadiran dimana hanya mencapai rata-rata score sebesar 3,66. Untuk lebih baik lagi perusahaan harus lebih tegas dan ketat dalam mengawasi kehadiran karyawannya supaya karyawan lebih tertib dan disiplin mengenai kehadiran.

2. Pada hasil analisisa kuesioner mengenai Motivasi Kerja pernyataan yang paling lemah adalah pada indikator kebutuhan rasa aman dimana hanya mencapai ratarata score sebesar 3,34. Untuk lebih baik lagi perusahaan di sarankan agar mengupayakan memberikan kompensasi/balas jasa sesuai dengan ketentuan yang di tetapkan pemerintah setempat. Agar karyawan merasa di perhatikan oleh perusahaan mengenai kesejahteraaan menumbuhkan motivasi kerja yang lebih baik lagi.

3. Pada hasil analisisa kuesioner mengenai Kinerja Karyawan pernyataan yang paling lemah lemah adalah pada indikator prestasi kerja, dimana hanya mencapai rata-rata score sebesar 3,54. Untuk lebih baik lagi dalam hal meningkatkan kinerja karyawan, perusahaan perlu mengevaluasi kinerja karyawan secara rutin, agar pencapaian target perusahaan bisa lebih meningkat lagi.

\section{DAFTAR PUSTAKA}

Hasibuan,M S.P (2020) .Manajemen Sumber Daya Manusia. Jakarta: Bumi Aksara

Hermawati, R., et al. (2020). The Effect of Trilogy Leadership Style and Organization Culture on School Performance: Evidence form Indonesian Senior High School. PalArch's Journal of Archaeology of Egypt/Egyptology, 17(6), 8512-8537.

Mangkunegara A P. (2017). Evaluasi Kinerja SDM, Refika Aditama: Bandung.

Nurjaya, N., et al. (2021). Pengaruh Kompetensi Sumber Daya Manusia Dan Kemampuan Pemanfaatan
Teknologi Terhadap Kinerja Aparatur Desa Pada Kantor Kepala Desa Di Kabupaten Gunungkidul, Yogyakarta. JENIUS (Jurnal Ilmiah Manajemen Sumber Daya Manusia), 4(3), 332-346.

Pawar, A., et al. (2020). Organizational Servant Leadership. International Journal of Educational Administration, Management, and Leadership, 63-76.

Prihantoro, A. (2015). Peningkatan Sumber Daya Manusia melalui Motivasi, Disiplin, Lingkungan Kerja, dan Komitmen, Yogyakarta : Deepublish

Santoso. (2015). Menguasai Statistik Multivariat. Jakarta: PT Elex Media Komputindo.

Sudjana. (2012). Manajemen dan Reformasi Pelayanan Publik dalam Konteks

Sugiono. (2017) Metode Penelitan Kualitatif, Kuantitatif dan $R$ \& $D$. Bandung : Alfabeta CV

Sunarsi, D., Wijoyo, H., Prasada, D., \& Andi, D. (2020, September). Pengaruh lingkungan kerja terhadap kinerja karyawan pada pt. Mentari persada di jakarta. In Seminar Nasional Manajemen, Ekonomi, Akuntansi (Vol. 5, No. 1, pp. 117-123).

Supangat. A (2015). Statistika Dalam Kajian Deskriptif, Inferensi, dan Nonparametrik.Jakarta : Kencana Prenada

Susilo (2015). Audit SDM.Yogyakarta : PT. Vorqistatama Binamega

Sutrisno, E (2017). Manajemen Sumber Daya Manusia. Jakarta : Kencana Prenada

Syaifuddin. (2018). Motivasi Dan Kinerja Pegawai Pendekatan Riset. Sidoarjo : Indomedia Pustaka

Wilandari, D. F., Sunarsi, D., \& Mas'adi, M. (2021). Pengaruh Penilaian Kerja Terhadap Kinerja Karyawan Pada PT. Jaya Mandiri Rekabuana di Cilandak. Jurnal Ekonomi Efektif, 3(2). 